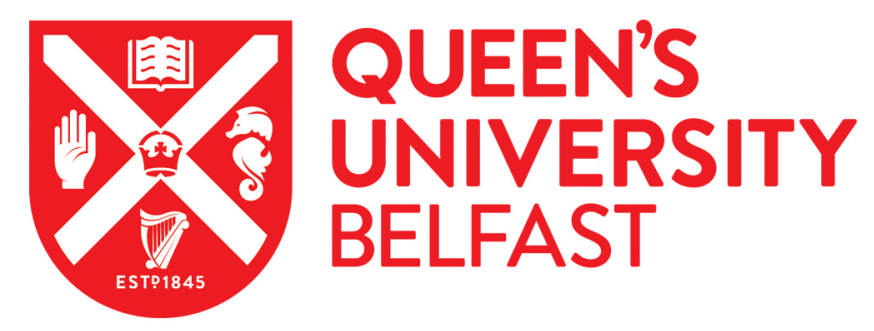

\title{
Did the Millennium Development Goals Change Trends in Child Mortality?
}

French, D. (2016). Did the Millennium Development Goals Change Trends in Child Mortality? Health Economics, 25(10), 1312-1325. https://doi.org/10.1002/hec.3218

\author{
Published in: \\ Health Economics
}

\section{Document Version:}

Peer reviewed version

Queen's University Belfast - Research Portal:

Link to publication record in Queen's University Belfast Research Portal

\section{Publisher rights}

Copyright (C) 2015 John Wiley \& Sons, Ltd.

This is the peer reviewed version of the following article: French, D. (2016) Did the Millennium Development Goals Change Trends in Child Mortality?. Health Econ., 25: 1312-1325., which has been published in final form at

http://onlinelibrary.wiley.com/wol1/doi/10.1002/hec.3218/abstract. This article may be used for non-commercial purposes in accordance with Wiley Terms and Conditions for Self-Archiving

\section{General rights}

Copyright for the publications made accessible via the Queen's University Belfast Research Portal is retained by the author(s) and / or other copyright owners and it is a condition of accessing these publications that users recognise and abide by the legal requirements associated with these rights.

Take down policy

The Research Portal is Queen's institutional repository that provides access to Queen's research output. Every effort has been made to ensure that content in the Research Portal does not infringe any person's rights, or applicable UK laws. If you discover content in the Research Portal that you believe breaches copyright or violates any law, please contact openaccess@qub.ac.uk. 


\title{
Did the Millennium Development Goals change trends in child mortality?
}

KEY WORDS: Millennium Development Goals, child mortality

\begin{abstract}
There has been little assessment of the role the MDGs have had in progressing international development. There has been a 41 per cent reduction in the under-5 mortality rate worldwide from 1990 to 2011 and an acceleration in the rate of reduction since 2000. This paper explores why this has occurred and results for all developing countries indicate that it is not due to more healthcare or public health interventions but is driven by a coincidental burst of economic growth. Although the MDGs are considered to have played an important part in securing progress against poverty, hunger and disease there is very little evidence to back this viewpoint up. A thorough analysis of the successes and failures of the MDGs is therefore necessary before embarking on a new round of global goals.
\end{abstract}

\section{Introduction}

In the Millennium Declaration in 2000, the UN General Assembly resolved to reduce under-five child mortality by two thirds of their existing rates by the year 2015. The most recent Millennium Development Goals Report 2013 reports a 41 per cent reduction in the child death rate worldwide from 1990 to 2011 and an acceleration in the rate of reduction globally and in many regions since 2000 (UN, 2013). While it is debatable whether the original ambitious target will be met by 2015 , this acceleration in progress since the Millennium Declaration is to be welcomed. In light of discussions to develop policy post-MDG, it is useful to ask the question: why has this improvement occurred? Was it due to the efforts of national governments and aid agencies in increasing public health expenditure, access to safe water, access to basic sanitation and immunisation rates or was it due to coincidental economic growth?

Although a thorough analysis of the impact of all the Millennium Development Goals is warranted, I focus here on child mortality for a number of reasons. First, the goal on reducing child mortality rates implicitly captures much of the content of all MDGs as child mortality can only be 
tackled by improving incomes, reducing hunger, enhancing gender equality and providing maternal health services etc. Children explicitly feature in seven out of the eight MDGs and four of the goals include targets on child health. Second, the goal of improving child health has been central to the objectives of international institutions for some time. Third, high child mortality (unlike combating HIV/AIDS for example) is an issue in most developing countries. Lastly, the data underlying the Millennium Development Goal on child mortality rates is of higher quality than for other target indicators.

Official monitoring reports mainly focus on the degree to which progress towards the MDGs has been achieved with little evaluation of whether the pace of progress has improved since the Millennium Declaration (UN, 2013 ; World Bank, 2013a). A number of academic studies have evaluated whether current levels of the MDG indicators are better or worse than predicted by historical trends (Klasen and Lange, 2012 ; Fukuda-Parr et al. 2013). In this paper, I focus on child mortality and analyse not only why improvements have occurred but also the degree to which the Millennium Declaration was responsible for these changes. Although the effect of the Declaration on resource mobilization and national development priorities has been considered elsewhere, an analysis of how this may have then impacted on child mortality is still currently lacking due to its perceived analytical difficulty (Kenny and Sumner, 2011 ; Molenaar, 2012).

Economic growth rates worldwide picked up significantly in the 2000s compared to the previous decade (OECD, 2010). The United Nations report that GDP per capita growth rates in developing countries were an impressive 5.8 per cent from 2000-2008 (UN, 2010). This acceleration is unrelated to the MDGs but can be attributed to a commodities boom, less conflict, new information and communication technologies as well as avoiding bad macroeconomic policies (Arbache and Page, 2010; Rodrik, 2011 ; Subramanian, 2011).

Higher GDP per capita is correlated with lower mortality at the country-level (Preston, 2007). Pritchett and Summers (1996) argued that 'wealthier nations are healthier nations' due to increased 
income buying greater quantities of health-enhancing public and private goods. Richer countries can expand the public provision of housing, healthcare and education (Anand and Ravallion, 1993) and have better institutions (Cutler et al., 2006) while richer individuals can purchase greater amounts of the inputs to good health for example nutrition, medicines and private healthcare (Schultz 1999; Gwatkin et al., 2007).

The response of child mortality to short run variations in incomes due to a recession or boom could however be different. A boom could allow greater consumption of nutritious foodstuffs, mosquito nets and medicines. However, a boom could also increase work opportunities making a mother's time more valuable which would draw her away from time-intensive activities such as antenatal and postnatal healthcare visits, breast-feeding, cooking healthy meals and collecting clean water (Baird et al., 2011). The composition of births can also change as the state of the economy varies with higher risk women deferring birth during a recession or suffering foetal loss through spontaneous abortion or still birth (Paxson and Schady, 2005).

In a review of the empirical literature on child mortality in developing countries, Ferreira and Schady (2009) find that child mortality is generally counter-cyclical (decreasing in booms and increasing in recessions). This finding contrasts with the pro-cyclicality of US child mortality (Dehejia and Lleras-Muney, 2004). Bhalotra (2010) argues that developing countries are different due to the lack of social welfare support and greater household credit constraints and finds that recessions in India drive mothers into distress working with reduced use of antenatal and postnatal healthcare facilities. Although the focus is on the mortality effect of recession, she finds no evidence of asymmetry in the effect of positive and negative macroeconomic shocks on infant mortality.

Many other factors impact on child health and there are other plausible explanations for greater progress in under-five mortality post-MDG. It is clear that the amount of resources available to developing countries for improving health has increased and, in the least developed countries, this has mainly been due to increases in foreign aid. Between 2002 and 2011, disbursements of ODA 
for health rose from US\$ 6.2 billion to US\$ 18.4 billion $($ WHO, 2013) and the positive effect of foreign aid on health outcomes has been established elsewhere (e.g. Arndt et al., 2011). Following the establishment of the Global Alliance for Vaccines and Immunization (GAVI) in 2000 over 250 million children were immunised with GAVI-supported vaccines (Clemens et al., 2010). Access to safe drinking water and basic sanitation has also been steadily improving since 1990 (WHO/UNICEF, 2013). These explanatory factors will all be considered in the analysis.

In September 2015, the UN General Assembly will agree on an expanded list of 17 sustainable development goals (SDGs) with 169 proposed targets. Frameworks for the SDGs should really consider first whether the original goals had any effect on outcomes including those related to health. It is clear that there have been substantial improvements in many social indicators since 2000 but it is not clear if these advances are attributable to the Millennium Declaration. The motivation for this paper is therefore to provide some analysis to ascertain whether the MDGs in particular changed trends in child mortality.

The paper is structured as follows: Section 2 introduces the methods; section 3 discusses the data; section 4 presents results and the final section concludes.

\section{Methods}

Consistent with the UNICEF Average Annual Rate of Reduction (AARR) methodology, Fukuda-Parr et al (2013) compare the percentage reduction in child mortality pre and post-MDG. This equates to comparing parameter estimates for the trend in a simple linear regression of $\log \left(Y_{t}\right)$ against time for each country before and after the year 2000 where $Y_{t}$ is under-five mortality. Writing $y_{t}$ for $\log \left(Y_{t}\right)$, we can use the single regression model

$$
y_{t}=\alpha_{1}+\alpha_{2} D_{t}+\tau_{1} \text { Trend }_{t}+\tau_{2}\left(D_{t} \text { Trend }_{t}\right)+\varepsilon_{t}
$$


where $D_{t}=0$ in 1990-1999 and $D_{t}=1$ in 2000-2010. A result of $\tau_{2}$ less than zero indicates an increase in the rate of decline of child mortality post-MDG. Aggregating across countries gives the panel model

$$
y_{i t}=\alpha_{1 i}+\alpha_{2 i} D_{t}+\tau_{1} \text { Trend }_{t}+\tau_{2}\left(D_{t} \text { Trend }_{t}\right)+\varepsilon_{i t}
$$

This model provides a simple test of the overall pace of progress in child mortality across all developing countries. It will also be used to determine if there has been any acceleration in progress in the determinants of child mortality.

The United Nations Road map towards the implementation of the Millennium Declaration identified unsafe water, malnutrition, inadequate immunization, lack of education and lack of access to basic health and social services as major contributing factors to child mortality (UN, 2001). Strategies to effect change included improving national standards and community practices for safe motherhood ; improving maternal and newborn health care status and access to services; and supporting programmes for immunization and vaccination, the use of oral rehydration therapy, nutrition and water and sanitation interventions. If national governments and aid agencies responded to this road map we should see significant increases in health expenditure, access to safe water, access to basic sanitation and immunisation rates post-MDGs. Including the contribution of a set of explanatory variables, $\boldsymbol{X}_{\boldsymbol{i t}}$, to rates of decline gives:

$$
y_{i t}=\alpha_{1 i}+\alpha_{2 i} D_{t}+\tau_{1} \text { Trend }_{t}+\tau_{2}\left(D_{t} \text { Trend }_{t}\right)+\boldsymbol{\beta} \boldsymbol{X}_{i t}+\varepsilon_{i t}
$$

The set of explanatory variables includes gross domestic product per capita, public health expenditure, private health expenditure, access to safe water, access to basic sanitation, the percentage of children receiving DPT vaccinations and the percentage of children receiving measles vaccinations. ${ }^{1}$ The trend terms here capture the trend in global levels of health technology. Similar formulations have been used elsewhere for analysing secular trends in child mortality and are

\footnotetext{
${ }^{1}$ Specifications with lags of the explanatory variables were also considered but results did not change appreciably.
} 
consistent with the theoretical framework used in health production function models (Thornton, 2002 ; Folland et al., 2007). Alternative specifications (for example Klasen and Lange, 2012) are not considered here. To control for endogeneity, the model will be estimated by the two-step generalised method of moments (GMM) estimator which is more efficient than the standard twostage least squares estimator in the presence of heteroskedasticity and autocorrelation (Schaffer, 2010). A number of alterative specifications for fixed effects and trend terms are also considered.

In aggregate analyses, results will be unweighted for population as the focus here is on how nations responded to the MDGs. At first sight, this may appear to be at odds with the Millennium Summit Declaration which was targeted at a global population. However, later announcements have often indicated that they were intended to be further applied at national level (UN, 2001) and much of the progress reports consider whether individual countries are on or off-track (UNDP, 2010 ; UN, 2013 ; World Bank, 2013a). Also this approach is natural since an achievement at global level driven by a few very populous countries and leaving many countries off-track would be unsatisfactory (Manning, 2009).

Results will be analysed across developing countries only as the focus of the MDGs is in practice mostly on developing countries (Manning, 2009). Although not an MDG in itself but an additional indicator of progress towards MDG 4, estimates of these models for infant mortality will also be considered.

\section{Data}

Infant (IMR) and under-five mortality (U5M) rates per 1,000 live births in 129 developing countries for years 1990-2010 were sourced from the World Development Indicators Database (World Bank, 2013b) and used in log form. These data were ultimately produced by the United Nations Interagency Group for Child Mortality Estimation (IGME). For most developing countries vital registration systems are incomplete and child deaths must be estimated using other sources which vary in data 
quality and availability. The main alternative source is complete or summary birth histories collected through censuses and surveys (e.g. Demographic and Health Surveys, Multiple Indicator Cluster Survey) and child mortality estimates based on these sources are subject to various data quality issues such as sampling error and recall bias as well as methodological biases in converting birth histories into mortality estimates. IGME therefore employ modelling approaches to smooth out irregularities and correct for biases. Although these have been recently further refined to flexibly capture changes in U5M rates over time (Alkema and New, 2013), they may unfortunately also remove informative temporal variation from the data creating a challenge for the empirical researcher to find statistically significant relationships.

Explanatory variables were sourced from the same dataset but were only available 19952010. The percentage of the population with access to an improved water source (for example piped water) (Water), the percentage of the population with access to improved sanitation facilities (for example piped sewer system) (Sanitation), the percentage of children ages 12-23 months who received diphtheria, pertussis and tetanus vaccinations $(I m m D P T)$ and the percentage of children ages 12-23 months who received measles vaccinations (ImmMeasles) were all entered into the model as given. Public health expenditure (Public HE) was found by multiplying total health expenditure per capita (adjusted for purchasing power parity and in constant 2005 \$) by the percentage which was public. This includes government spending and donations from international agencies and nongovernmental organizations. The remainder was then regarded as private health expenditure (Private HE). These were then logged. Gross Domestic Product per capita (adjusted for PPP and in constant 2005 \$) (GDP) was sourced from Penn World Tables v.7.1 (Heston et al., 2012) and used in log form.

These data were complete over 1995-2010 for 112 countries while the remaining 17 countries had some missing data for some of these variables. The remaining six developing countries had insufficient data to be included. 


\section{Results}

\subsection{Main results}

Unweighted means for 129 developing countries are given for all variables in Table 1 for selected years. Both under-five and infant mortality have fallen over this period and the explanatory variables which are all plausibly mortality-reducing have generally been rising. It is clear that a substantial proportion of deaths to children before reaching their fifth birthday occur in infancy.

\section{[TABLE 1 HERE]}

The distribution of under-five mortality rates by country for 1990, 2000 and 2010 are plotted in Fig 1. There is a noticeable secular shift towards lower mortality rates. The most striking change is in the right-tail. For example, death rates at the $90^{\text {th }}$ percentile fell pre-MDG by 15 per cent from 202 per 1000 births in 1990 to 171 per 1000 births in 2000 then post-MDG by 35 per cent to 112 per 1000 births in 2010. In the first instance then, model 1 was used to determine if rates of decline were consistently faster for each developing country after the year 2000.

\section{[FIGURE 1 HERE]}

Results in Table 2 indicate that slightly over two-thirds of developing countries (68\%) have had accelerated improvement in under-five mortality since 2000. In 91 per cent of countries in subSaharan Africa, under-five mortality has declined more rapidly post-2000 compared to pre-2000. Rates of decline have also accelerated in the majority of developing countries in every region except Latin America and East Asia. Table 8 in Fukuda-Parr et al (2013) has generally lower numbers of countries improving post-MDG in each region. This is due to their inclusion of non-developing countries and to more recent improvements in the accuracy of data (Alkema and New, 2013). Applying the stricter criterion of a statistically significant accelerated improvement does not change 
the overall picture although progress in Latin America becomes even scarcer. Infant mortality has followed a similar pattern but faster progress has been slightly more extensive. The rest of this paper will explore why faster progress has generally occurred.

\section{[TABLE 2 HERE]}

The individual country results can be aggregated using a panel approach (model 2) and allow the estimation of an average increase in the pace of decline for developing countries (Table 3). Under-five mortality was declining in developing countries at an annual rate of 2.5 per cent pre-MDG and the annual rate of decline was a statistically significant 1.5 per cent faster after the Millennium Declaration implying a total percentage reduction of 58 per cent from 1990 to 2015 . $^{2}$ For a country to have successfully reached the MDG of a reduction by two thirds from 1990 to 2015, the annual rate of reduction would have had to be 4.3 per cent throughout this period. ${ }^{3}$ Nevertheless, at first glance, it would appear that there was a significant change in child mortality after the Millennium Declaration. The pattern of infant mortality over this period is very similar with at an annual rate of reduction of 2.3 per cent pre-2000 and 1.3 per cent faster post-2000.

\section{[TABLE 3 HERE]}

To understand whether the determinants of child mortality have changed, a number of potential explanatory variables have been analysed pre and post-MDG. The data here are generally more limited and so the model in (2) is applied to the periods 1995-1999 and 2000-2010. A positive increase in any of these variables would be expected to improve child mortality. A general trend upwards in these variables over the whole period 1995-2010 is clear from the first row of Table 4 although statistically insignificant for DPT immunisation rates. The second row indicates that a minority of these variables displayed more rapid progress in the period 2000-2010 compared to 1995-1999 (i.e. $\tau_{2}>0$ ). There have been significant improvements in GDP per capita and public

\footnotetext{
${ }^{2}(1-0.025)^{10} *(1-0.040)^{15}=0.42$

${ }^{3}$ Since $(1-0.043)^{25}=0.33$
} 
health expenditure with annual growth rates increasing by 1.3 per cent and 3.5 per cent respectively post-MDG. The annual trend in the percentage of one-year olds being immunised for DPT increased by 0.59 percentage points after the Millennium Declaration. None of the other potential explanatory variables showed any noticeable increase post-MDG. The very large standard errors for immunisation rates and relatively low $\mathrm{R}^{2}$ indicate large variation around the overall positive trend. Measles immunization activities have accelerated in target countries since 2000 (WHO, 2014) but trends in measles immunisation rates have also declined elsewhere. In a country-by-country analysis (not shown), 56 countries showed a decline in trend post-MDG ranging from 0.05 percentage points lower annually in Tonga to 10.5 percentage points lower annually in Venezuela. In many countries, this was due to having already reached close to universal coverage by 2000.

\section{[TABLE 4 HERE]}

In order to assess the relative contribution of these variables to progress towards Goal 4, the model in (3) was estimated. It is conventional to model mortality, GDP and health expenditure in log form. An unlogged form for the remaining variables (Water, Sanitation, ImmDPT and ImmMeasles) which are all expressed in percentages allows for a convenient interpretation as a one percentage point increase in $X_{j}$ can then be said to cause a $100 \beta_{j}$ per cent change in the under-five mortality rate. This functional form is validated by statistical testing (Table 5). Model 3 with the remaining variables all unlogged (labelled M1) is tested against the same model with these variables all logged (M2). For both the Davidson-MacKinnon test (J test) and the Cox and Pesaran test, the unlogged specification is accepted (first row) and the logged specification rejected (second row) at the five per cent significance level. See Greene (2012) for details on these tests.

\section{[TABLE 5 HERE]}

The trend terms in model (3) representing trends in global levels of health technology are assumed exogenous. However, it is unclear whether a priori the other explanatory variables should 
be treated as exogenous or endogenous in estimation. Both public and private health care expenditure would be expected to increase in a year with especially high child mortality which would lead to reverse causation. It is less likely but possible that access to water and sanitation facilities and immunization rates should also be contemporaneously correlated with shocks to child mortality. In Baird et al (2011), it is assumed that infant mortality does not reverse cause income while in Farahani et al (2009) income is regarded as endogenous. Estimates are given in Table 6 for the case of all exogenous explanatory variables ('OLS') and for the case of all endogenous explanatory variables ('IV-GMM') where the variables are instrumented by their values lagged by one to three years.

[TABLE 6 HERE]

In the OLS estimates with under-five mortality as dependent variable, few of the explanatory variables are statistically significant at the five per cent level. GDP per capita is significant in explaining under-five mortality. A one per cent increase in GDP per capita decreases under-five mortality by about 0.14 per cent. Immunisation against measles has also reduced deaths before five years of age. Increasing measles immunisation rates in a country by one percentage point decreases child death rates by 0.1 per cent. In addition, an increase in the percentage of the population with access to basic sanitation by one percentage point decreases child mortality by 0.6 per cent. There is a significant downwards trend of under-five mortality of 1.8 per cent per year which is unaccounted for by these explanatory variables reflecting global technological improvements or changes in unobserved variables.

There is evidence of endogeneity and therefore the IV-GMM estimates are to be preferred. The endogeneity test rejects the null of exogenous regressors testing all seven explanatory variables. The OLS estimates are therefore likely to be biased although, a priori, the direction of the bias is uncertain. Where there is reverse causation of child mortality on the explanatory variables, OLS estimates will exaggerate their effect and coefficient estimates will be biased away from the null. On 
the other hand, effects may actually be underestimated in the OLS model. First, the explanatory variables used here will undoubtedly be subject to measurement error which is eliminated by instrumenting and measurement error causes effects on child mortality in the OLS model to be underestimated. Second, the direction of the endogeneity bias is ambiguous in multivariate regression (Ettner, 1996). Second-order effects through correlations of any variable with the other regressors may change the predicted sign of the bias; it is therefore possible that eliminating endogeneity may lead to a larger estimate rather than a smaller estimate of the effect of any particular variable on child mortality.

Using the IV-GMM estimates, the effect of income on child mortality is seen to be larger than before: a one per cent increase in GDP per capita decreases under-five mortality by about 0.18 per cent. This would imply a six per cent reduction in under-five mortality due to economic growth from 2000 to 2010 since average GDP per capita grew by 33 per cent over this period.

Increasing measles immunisation rates in a country by one percentage point now decreases child death rates by 0.5 per cent. This estimate is reasonable. Average measles immunization rates increased by 7.5 percentage points between 2000 and 2010 in the 129 developing countries considered while measles mortality fell by 3.1 deaths per 1000 births or 3.9 per cent of the underfive mortality rate in 2000 (author's calculations based on WDI Database and CHERG, 2014). This implies increasing measles immunisation rates by one percentage point decreases child death rates by 0.5 per cent. Access to safe drinking water now has a statistically significant effect on child mortality whereas improving basic sanitation does not have a significant effect. An increase in the percentage of the population with access to improved water facilities by one percentage point decreases child mortality by 0.6 per cent. There is a slightly larger downwards trend than before of under-five mortality of 2.4 per cent per year but no improvement in trend post-MDG. The coefficient on DPT immunisation which suggests rising immunisation rates increase under-five mortality appears counterintuitive at first glance. However this is consistent with studies showing that DPT- 
vaccinated children especially girls have significantly higher mortality than DPT-unvaccinated children in high-mortality countries in Africa and Asia (Aaby et al., 2012) perhaps due to the DPT vaccine being administered too early (Valentiner-Branth et al., 2007) or in conjunction with the live measles vaccine (Breiman et al., 2004; Chan et al, 2007) or as a booster in the second year of life.

Public health expenditure does not appear to have made any difference to child survival. There is some evidence, at least in the poorest countries, that improving child health was not a priority for national governments during this period. Although, as reported earlier, disbursements of ODA for health tripled between 2002 and 2011, much of this went towards fighting HIV/AIDS. Spending on MDG 6 (combating HIV/AIDS, malaria and other diseases) increased five-fold in this period and during 2009-2011, 58 per cent of ODA for health went to MDG 6 (WHO, 2013). In a review of policy documents of 21 aid programmes, Fukuda-Parr (2008) found surprisingly limited emphasis on child survival in donor priorities. She also found in 22 national poverty reduction strategies that the health priority was HIV/AIDS and less explicitly child survival and maternal health.

Also reported are tests for misspecification. The standard specification test for instrument validity in two-step GMM is the Hansen J-test and this test also indicates whether the instruments are correctly excluded from the model. This test is consistent in the presence of heteroskedasticity and autocorrelation. The Hansen test statistic estimated here indicates that the null hypothesis of valid instruments and no misspecification is accepted. The underidentification test shows that the instruments are correlated with the endogenous regressors and hence are not weak. The number of observations available for IV-GMM estimation is reduced from the OLS estimation as there are no instruments for the first three years from the period 1995-2010 for each country.

Results for infant mortality rates are very similar. Coefficient estimates of GDP per capita, safe drinking-water access, immunisation rates and the trend term for the IV-GMM specification are statistically significant and are of the same order as for under-five mortality. Safe drinking water access and measles immunisation have less effect on infant mortality than on under-five mortality. 
As the average infant mortality over this period in these countries was 45.8 deaths per 1000 live births, the estimate of the effect of average income on infant mortality here - one per cent increase in GDP per capita decreases infant mortality by 0.20 per cent - equates to a one per cent increase in GDP per capita approximately decreasing infant mortality by 0.09 deaths. This is conservative compared to the 0.24 to 0.40 change in infant mortality per 1,000 births reported in Baird et al. (2011) where the authors use Demographic and Health Survey data.

To explain the acceleration in the downwards trend of under-five mortality post-2000, an explanatory variable has to have a statistical relationship with under-five mortality of the correct sign and has to exhibit an increasing trend post-2000. Increasing measles immunisation, access to safe water and economic growth all explain under-five mortality (Table 6) but of these only economic growth improved at a faster rate post-MDG (Table 4). The only available explanation for accelerated progress towards Goal 4 after the Millennium Declaration is therefore economic growth. This conclusion is reinforced graphically in figure 2 . The cross-country average of under-5 mortality rates is calculated and its annual rate of decrease is displayed for each year over 2000-2010 (Observed). There is a clear acceleration in the downwards trend over this decade going from an annual decrease of 3.0 per cent in 2000 to 3.9 per cent in 2008 slowing down to 2.6 per cent in 2010 . The estimate for the trend from Table 6 - 2.4 per cent decrease annually - is also graphed (Trend_effect). Applying the statistically significant estimates from Table 6 to annual changes in cross-country averages of the corresponding variables we get the GDP effect, Water effect and Immunization effect. The only one of these effects to increase over this decade is the GDP effect. The change in GDP per capita has almost no effect on under-five mortality in 2001 but becomes steadily greater every year until it is reducing under-five mortality annually by almost 0.9 per cent in 2006 and 2007. The slowdown in the annual growth in GDP per capita at the end of the decade mirrors the slow-down in the downwards trend in under-five mortality. In addition, we see that the most substantial factor explaining annual change in under-five mortality over most of the decade (20032008) was economic growth. This has been neglected in policy discussions where child mortality 
reductions have generally been attributed to initiatives related to the Millennium Development Goals.

[FIGURE 2 HERE]

\subsection{Robustness checks}

The specification in model (3) was chosen so as to maintain consistency with models (1) and (2) but it can be shown that the results in the previous section are robust to a number of alternative specifications. The model in (3) with the level break terms $\left(\alpha_{2 i}\right)$ and trend break term $\left(\tau_{2}\right)$ omitted are first considered:

$$
y_{i t}=\alpha_{1 i}+\tau_{1} \text { Trend }_{t}+\boldsymbol{\beta} \boldsymbol{X}_{i t}+\varepsilon_{i t}
$$

Time effects $\left(\tau_{t}\right)$ common across all countries are then used instead of the trend and trend break terms:

$$
y_{i t}=\alpha_{1 i}+\alpha_{2 i} D_{t}+\tau_{t}+\boldsymbol{\beta} \boldsymbol{X}_{i t}+\varepsilon_{i t}
$$

The level break terms are then omitted from model 3b:

$$
y_{i t}=\alpha_{1 i}+\tau_{t}+\boldsymbol{\beta} \boldsymbol{X}_{i t}+\varepsilon_{i t}
$$

In the last specification, country-specific trends are used instead of global trends:

$$
y_{i t}=\alpha_{1 i}+\tau_{1 i} \text { Trend }_{i t}+\boldsymbol{\beta} \boldsymbol{X}_{i t}+\varepsilon_{i t}
$$

The models are estimated for under-5 mortality using the two-step GMM estimator as before and results are presented in Table 7 along with the corresponding estimates from the previous section (model 3). All models are seen to be well-specified. Not surprisingly, the goodness of fit statistic $\mathrm{R}^{2}$ decreases when country-specific parameters are dropped (e.g. 3a vs. 3) while there is no change when time effects are used instead of trend terms ( $3 b$ and $3 c$ vs. 3 and $3 a$ ). Income is statistically significant in each specification. Coefficients increase when the level breaks are dropped ( $3 a$ and $3 c$ ) and decrease when country-specific trends are included (3d) although they still remain well within 
the confidence interval of the estimate from the original model (95\% confidence interval using the estimate of -0.178 is $[-0.084,-0.272])$. The other variables previously identified as statistically significant - Water, ImmDPT and ImmMeasles - remain so except in the final estimates.

\section{[TABLE 7 HERE]}

Although results are robust to specification, a number of caveats should be taken into account when making definitive conclusions based on the analysis presented here. Estimates given are for all developing countries taken as whole and may mask the significant contribution of factors unrelated to economic growth in particular regions. For example, it might be expected that the marginal effect of increasing health expenditure would be substantial in the least developed countries where current levels of health spending are lowest. In addition, the model of the determinants of child health mortality is incomplete due to a lack of data. It is possible that some element of public spending on health may have been particularly effective in reducing child mortality but disaggregated health spend by country over time is not available. For example, the use of insecticide-treated bed nets rapidly increased in Sub-Saharan Africa from 2005 to 2011 (WHO, 2013) but data on their usage across countries and over time is limited. Also, the irrelevance of health expenditure (which includes aid flows) to child mortality could be due to resources being used to prevent the situation getting worse due to the AIDS pandemic (as intimated by Kenny and Sumner, 2011). This is probably not the case as AIDS causes only a small fraction of deaths among children under-five in the countries considered here - 2.71 per cent in 2000 and 2.16 per cent in 2010 (author's calculations based on CHERG, 2014). 


\section{Conclusion}

The MDGs are considered by policy makers and civil society to have played an important part in securing progress against poverty, hunger and disease (Sachs, 2012). If national governments and aid agencies responded to the Millennium Declaration in the manner originally envisaged, the data should indicate significant increases in public health expenditure, access to safe water, access to basic sanitation and immunisation rates post-MDG and these changes should have made a difference to child mortality rates.

From the analysis in this paper, it would appear that the Millennium Development Goals did not change trends in child mortality across the total sample of 129 developing countries considered. It is clear that there has been acceleration in the rate of reduction of under-five mortality rates from 2000-2010. But across all countries considered, there is no evidence that rates of growth in private health expenditure accelerated or that trends in access to improved water sources, improved sanitation facilities or measles immunisation rates have improved. Growth rates in public health expenditure and the trend in DPT immunisation rates have been faster post-MDG but these have not caused child death rates to fall. In contrast, many countries have experienced rapid economic growth during this period. Income per capita is seen to clearly influence the child mortality rate and this relationship is robust when accounting for endogeneity or a variety of model specifications. The pattern of accelerating economic growth and a slowdown towards the end of the decade in developing countries is also clearly reflected in secular trends in under-five mortality. Furthermore, the most significant factor explaining annual decreases in child mortality over the decade was economic growth.

A thorough analysis of the successes and failures of the Millennium Development Goals would be welcome before embarking on a new round of global goals. The vast resources mobilized due to this initiative have undoubtedly progressed international development. But what is not clear 
is where such effects have taken place and to what extent the MDGs were responsible. This paper is intended to provide an initial investigation. 


\section{References}

Aaby, P., Benn, C., Nielsen, J., Lisse, I. M., Rodrigues, A., \& Ravn, H. (2012). Testing the hypothesis that diphtheria-tetanus-pertussis vaccine has negative non-specific and sex-differential effects on child survival in high-mortality countries. BMJ Open, 2(3), 10.1136/bmjopen-2011-000707.

Alkema, L., \& New, J. R. (2013). Global estimation of child mortality using a bayesian B-spline bias-reduction method. ArXiv Preprint arXiv:1309.1602.

Anand, S., \& Ravallion, M. (1993). Human development in poor countries: On the role of private incomes and public services. Journal of Economic Perspectives 7 : 133-150.

Arbache, J. S., \& Page, J. (2010). How fragile is Africa's recent growth? Journal of African Economies 19 : 1-24.

Arndt, C. , Jones, S. and F. Tarp (2011). Aid effectiveness: Opening the black box. World Institute for Development Economics Research, Working paper, No. 2011/44.

Baird, S., Friedman, J., \& Schady, N. (2011). Aggregate income shocks and infant mortality in the developing world. Review of Economics and Statistics 93 : 847-856.

Bhalotra, S. (2010). Fatal fluctuations? cyclicality in infant mortality in India. Journal of Development Economics 93 : 7-19.

Breiman, R. F., Streatfield, P. K., Phelan, M., Shifa, N., Rashid, M., \& Yunus, M. (2004). Effect of infant immunisation on childhood mortality in rural bangladesh: Analysis of health and demographic surveillance data. The Lancet 364 : 2204-2211.

Chan, G. J., Moulton, L. H., Becker, S., Munoz, A., \& Black, R. E. (2007). Non-specific effects of diphtheria tetanus pertussis vaccination on child mortality in Cebu, the Philippines. International Journal of Epidemiology 36 : 1022-1029.

CHERG. (2014). Child causes of death annual estimates by country 2000-10. http://cherg.org/datasets.html [3 December 2013]

Clemens, J., Holmgren, J., Kaufmann, S. H., \& Mantovani, A. (2010). Ten years of the global alliance for vaccines and immunization: Challenges and progress. Nature Immunology 11 : 1069.

Cutler, D., Deaton, A., \& Lleras-Muney, A. (2006). The determinants of mortality. The Journal of Economic Perspectives 20 : 97-120.

Dehejia, R., \& Lleras-Muney, A. (2004). Booms, busts, and babies' health. The Quarterly Journal of Economics 119 : 1091-1130.

Ettner, S. L. (1996). New evidence on the relationship between income and health. Journal of Health Economics 15 : 67-85.

Farahani, M., Subramanian, S. V., \& Canning, D. (2009). The effect of changes in health sector resources on infant mortality in the short-run and the long-run: A longitudinal econometric analysis. Social Science \& Medicine 68 : 1918-1925.

Ferreira, F. H., \& Schady, N. (2009). Aggregate economic shocks, child schooling, and child health. The World Bank Research Observer 24 : 147-181.

Folland, S., Goodman, A. C., \& Stano, M. (2007). The economics of health and health care, Pearson Prentice Hall Upper Saddle River, NJ.

Fukuda-Parr, S. (2008). Are the MDGs priority in development strategies and aid programmes? Only few are!, Working Paper No. 48, International Poverty Centre for Inclusive Growth (UNDP).

Fukuda-Parr, S., Greenstein, J., \& Stewart, D. (2013). How should MDG success and failure be judged: Faster progress or achieving the targets? World Development 41 : 19-30.

Greene, W. (2012). Econometric analysis (7th ed.). Pearson Education, England. 
Gwatkin, D. R., Rutstein, S., Johnson, K., Suliman, E., Wagstaff, A., Gonzalez-Castell, D., et al. (2007). Socioeconomic differences in health nutrition and population within developing countries. an overview. Salud Publica De Mexico 49 : 345-356.

Heston, A., Summers, R., \& Aten, B. (2012). Penn World Table version 7.1. (Nov 2012 ed.) Center of comparisons of production, income and prices at the University of Pennsylvania.

Hulme, D. \& Scott, J. (2010) The Political Economy of the MDGs: Retrospect and Prospect for the World's Biggest Promise. New Political Economy 15.2, 293-306.

Kaler, S. G. (2008). Diseases of poverty with high mortality in infants and children. Annals of the New York Academy of Sciences 1136 : 28-31.

Kenny, C., \& Sumner, A. (2011). More money or more development: What have the MDGs achieved. Center for Global Development Working Paper 278.

Klasen, S., \& Lange, S. (2012). Getting progress right: Measuring progress towards the MDGs against historical trends. No. 87. Courant Research Centre: Poverty, Equity and Growth-Discussion Papers.

Liu, L., Johnson, H. L., Cousens, S., Perin, J., Scott, S., Lawn, J. E., et al. (2012). Global, regional, and national causes of child mortality: An updated systematic analysis for 2010 with time trends since 2000. The Lancet 379 : 2151-2161.

Molenaar, B. (2012). Do we need a new POST-2015 framework to promote health-related goals ? Health Diplomacy Monitor 3 : 7-10.

OECD. (2010). Perspectives on global development 2010: Shifting wealth OECD.

Paxson, C., \& Schady, N. (2005). Child health and economic crisis in Peru. The World Bank Economic Review 19 : 203-223.

Preston, S. H. (2007). The changing relation between mortality and level of economic development. International Journal of Epidemiology 36 : 484-490.

Pritchett, L., \& Summers, L. H. (1996). Wealthier is healthier. The Journal of Human Resources 31 : 841-868.

Rodrik, D. (2011). The Future of Economic Convergence, NBER Working Paper 17400.

Sachs, J. D. (2012). From millennium development goals to sustainable development goals. The Lancet 379 : 2206-2211.

Schaffer, M. E. (2010.). xtivreg2: Stata module to perform extended IV/2SLS, GMM and AC/HAC, LIML and kclass regression for panel data models. http://ideas.repec.org/c/boc/bocode/s456501.html

Stuckler, D., Basu, S., \& McKee, M. (2010). Drivers of inequality in millennium development goal progress: A statistical analysis. PLoS Medicine 7241.

Subramanian, A. (2011). Eclipse: Living in the shadow of china's economic dominance, Peterson Institute for International economics, Washington D.C.

The Economist (2015), The 169 commandments, Issue Mar 28th 2015.

Thornton, J. (2002). Estimating a health production function for the US: Some new evidence. Applied Economics 34 : 59-62.

UN (2001). Road map towards the implementation of the United Nations Millennium Declaration. United Nations : New York.

UN. (2010). World economic situation and prospects - statistical annex, United Nations Conference on Trade and Development, United Nations. Dept. of Economic and Social Affairs, New York.

UN. (2013). Millennium development goals report . United Nations, New York.

UNDG. (2005), Making the MDGs matter: A country perspective, report of a UNDG survey. United Nations Development Group, New York.

UNDP. (2010). Beyond the midpoint - achieving the millenium devlopment goals. United Nations Development Programme, New York. 
Valentiner-Branth, P., Perch, M., Nielsen, J., Steinsland, H., Garly, M., Fischer, T. K., et al. (2007). Community cohort study of cryptosporidium parvum infections: Sex-differential incidences associated with BCG and diphtheria-tetanus-pertussis vaccinations. Vaccine 25 : 2733-2741.

WHO (2013). World health statistics. World Health Organisation, Geneva.

WHO (2014). Measles fact sheet $N^{\circ} 286$. http://www.who.int/mediacentre/factsheets/fs286/en/ [3 March 2014]

WHO/UNICEF. (2013). Progress on sanitation and drinking water . World Health Organization and UNICEF. Geneva / New York.

World Bank. (2013a). Global monitoring report 2013 : Rural-urban dynamics and the millennium development goals. International Bank for Reconstruction and Development / The World Bank, Washington DC.

World Bank. (2013b). World Development Indicators Database, http://data.worldbank.org/data-catalog/worlddevelopment-indicators [1 November 2013] 
Table 1 : Unweighted means across developing countries 1990-2010 for selected years

\begin{tabular}{|c|c|c|c|c|c|c|c|c|c|}
\hline Year & $\begin{array}{c}\text { Under-5 } \\
\text { mortality } \\
\text { (per 1000) }\end{array}$ & $\begin{array}{c}\text { Infant } \\
\text { mortality } \\
\text { (per 1000) }\end{array}$ & $\begin{array}{c}\text { GDP } \dagger \\
(\$ \text { per cap. })\end{array}$ & $\begin{array}{c}\text { Public } \\
\text { Health Exp } \dagger \\
(\$ \text { per cap. })\end{array}$ & $\begin{array}{c}\text { Private } \\
\text { Health Exp } \dagger \\
\text { (\$ per cap.) }\end{array}$ & $\begin{array}{c}\text { Water } \\
\text { access } \\
(\%) \\
\end{array}$ & $\begin{array}{c}\text { Sanitation } \\
\text { access } \\
(\%) \\
\end{array}$ & $\begin{array}{c}\text { Immuniz. } \\
\text { DPT } \\
(\%) \\
\end{array}$ & $\begin{array}{c}\text { Immuniz. } \\
\text { Measles } \\
(\%) \\
\end{array}$ \\
\hline 1990 & 93 & 63 & - & - & - & - & - & - & - \\
\hline 1992 & 90 & 60 & - & - & - & - & - & - & - \\
\hline 1994 & 87 & 58 & - & - & - & - & - & - & - \\
\hline 1996 & 83 & 56 & 3778 & 99 & 74 & 75 & 54 & 76 & 76 \\
\hline 2000 & 75 & 51 & 4047 & 115 & 88 & 77 & 57 & 78 & 77 \\
\hline 2002 & 70 & 48 & 4121 & 129 & 94 & 78 & 58 & 79 & 79 \\
\hline 2004 & 65 & 45 & 4395 & 149 & 109 & 80 & 59 & 81 & 80 \\
\hline 2006 & 60 & 42 & 4820 & 171 & 126 & 81 & 60 & 84 & 83 \\
\hline 2008 & 55 & 39 & 5208 & 201 & 144 & 82 & 61 & 85 & 84 \\
\hline
\end{tabular}

$\dagger$ Adjusted for purchasing power parity and in constant $2005 \$$.

Table 2 : Percentage of developing countries with faster progress in child mortality post-MDG

\begin{tabular}{|c|c|c|c|c|c|}
\hline \multirow[t]{2}{*}{ Region } & \multirow[t]{2}{*}{ Total } & \multicolumn{2}{|c|}{ Faster progress } & \multicolumn{2}{|c|}{$\begin{array}{c}\text { Faster progress } \\
\text { post-MDG : IMR }\end{array}$} \\
\hline & & $\tau_{2}<0$ & $\begin{array}{c}\tau_{2}<0 \\
\text { at } 5 \% \\
\text { level }\end{array}$ & $\tau_{2}<0$ & $\begin{array}{c}\tau_{2}<0 \\
\text { at } 5 \% \\
\text { level }\end{array}$ \\
\hline East Asia \& Pacific & 19 & $42 \%$ & $42 \%$ & $42 \%$ & $42 \%$ \\
\hline Europe \& Central Asia & 19 & $79 \%$ & $79 \%$ & $79 \%$ & $79 \%$ \\
\hline Latin America \& Caribbean & 26 & $31 \%$ & $19 \%$ & $46 \%$ & $38 \%$ \\
\hline Middle East \& North Africa & 12 & $75 \%$ & $75 \%$ & $92 \%$ & $83 \%$ \\
\hline South Asia & 8 & $88 \%$ & $88 \%$ & $88 \%$ & $75 \%$ \\
\hline Sub-Saharan Africa & 45 & $91 \%$ & $87 \%$ & $91 \%$ & $87 \%$ \\
\hline Total & 129 & $68 \%$ & $64 \%$ & $73 \%$ & $68 \%$ \\
\hline
\end{tabular}

The percentage of countries with $\tau_{2}<0$ in equation (1) is reported. The hypothesis test is one-sided at $5 \%$ level. Standard errors used in hypothesis tests are robust to autocorrelation and heteroskedasticity. 
Table 3 : Panel estimate of progress in child mortality 1990-2010

\begin{tabular}{lcc}
\hline \hline & $\log (\mathrm{U} 5 \mathrm{M})$ & $\log (\mathrm{IMR})$ \\
\hline Trend, $\tau_{1}$ & $-0.025^{* *}$ & $-0.023^{* *}$ \\
& $(0.001)$ & $(0.001)$ \\
& & \\
Trend $(\geq 2000), \tau_{2}$ & $-0.015^{* *}$ & $-0.013^{* *}$ \\
& $(0.002)$ & $(0.002)$ \\
\hline No. of observations & 2709 & 2709 \\
No. of countries & 129 & 129 \\
$R^{2}$ & 0.91 & 0.90 \\
\hline \hline
\end{tabular}

$* p<0.05, * * p<0.01$ Estimation of equation (2) is by fixed-effects. Standard errors in parentheses are robust to heteroskedasticity and autocorrelation.

Table 4 : Panel estimate of progress in the determinants of child mortality 1995-2010

\begin{tabular}{lccccccc}
\hline \hline & $\log (\mathrm{GDP})$ & $\log ($ PublicHE $)$ & $\log$ (PrivateHE) & Water & Sanitation & ImmDPT & ImmMeasles \\
\hline Trend, $\tau_{1}$ & $0.018^{* *}$ & $0.047^{* *}$ & $0.055^{* *}$ & $0.576^{* *}$ & $0.583^{* *}$ & 0.337 & $0.477^{*}$ \\
& $(0.003)$ & $(0.006)$ & $(0.005)$ & $(0.042)$ & $(0.039)$ & $(0.185)$ & $(0.198)$ \\
Trend $(\geq 2000), \tau_{2}$ & $0.013^{* *}$ & $0.035^{* *}$ & 0.009 & 0.006 & -0.002 & $0.588^{* *}$ & 0.337 \\
& $(0.004)$ & $(0.007)$ & $(0.005)$ & $(0.049)$ & $(0.045)$ & $(0.210)$ & $(0.219)$ \\
\hline No. of observations & 2064 & 2035 & 2035 & 2040 & 2036 & 2045 & 2045 \\
No. of countries & 129 & 129 & 129 & 129 & 129 & 129 & 129 \\
$R^{2}$ & 0.73 & 0.70 & 0.74 & 0.80 & 0.83 & 0.49 & 0.45 \\
\hline \hline
\end{tabular}

$* p<0.05, * * p<0.01$ Estimation of equation (2) is by fixed-effects. Standard errors in parentheses are robust to heteroskedasticity and autocorrelation.

Table 5 : Non-nested hypothesis tests to select between alternative functional form specifications

\begin{tabular}{ccccc}
\hline \hline & \multicolumn{2}{c}{ J test for non-nested models } & \multicolumn{2}{c}{ Cox-Pesaran test for non-nested models } \\
\cline { 2 - 5 } & Distribution & Test statistic & Distribution & Test statistic \\
\hline H0:M1 / H1:M2 & $\mathrm{t}(1717)$ & 1.52 & $\mathrm{~N}(0,1)$ & -1.17 \\
H0:M2 / H1:M1 & $\mathrm{t}(1718)$ & $9.98^{* *}$ & $\mathrm{~N}(0,1)$ & $-15.86^{* *}$ \\
\hline \hline
\end{tabular}

$* p<0.05, * * p<0.01$. Models are

$M 1: y_{i t}=\beta_{4}$ Water $_{i t}+\beta_{5}$ Sanitation $_{i t}+\beta_{6}$ ImmDPT $_{i t}+\beta_{7}$ ImmMeasles $_{i t}+\mathbf{\Gamma Z}_{\mathbf{i t}}+v_{i t}$

$M 2: y_{i t}=\beta_{4} \log \left(\right.$ Water $\left._{i t}\right)+\beta_{5} \log \left(\right.$ Sanitation $\left._{i t}\right)+\beta_{6} \log \left(\right.$ ImmDPT $\left._{i t}\right)+\beta_{7} \log \left(\right.$ ImmMeasles $\left._{i t}\right)+\mathbf{\Gamma Z}_{\mathbf{i t}}+v_{i t}$

where $\boldsymbol{\Gamma Z}_{\mathbf{i t}}=\beta_{1} \log \left(G D P_{i t}\right)+\beta_{2} \log \left(\right.$ PublicH $\left.E_{i t}\right)+\beta_{3} \log \left(\right.$ PrivateH $\left._{i t}\right)+\alpha_{1 i}+\alpha_{2 i} D_{t}+\tau_{1}$ Trend $t+\tau_{2}\left(D_{t}\right.$ Trend $\left.t\right)$ and $y_{i t}$ is $\log (\mathrm{U} 5 \mathrm{M})$ 
Table 6 : Regression results

\begin{tabular}{|c|c|c|c|c|}
\hline & \multicolumn{2}{|c|}{$\log \mathrm{U} 5 \mathrm{M}$} & \multicolumn{2}{|c|}{ log IMR } \\
\hline & OLS & IV-GMM & OLS & IV-GMM \\
\hline$\beta_{1}, \log$ GDP & $\begin{array}{c}-0.137^{* *} \\
(0.035)\end{array}$ & $\begin{array}{c}-0.178^{* *} \\
(0.048)\end{array}$ & $\begin{array}{c}-0.147^{* *} \\
(0.032)\end{array}$ & $\begin{array}{c}-0.197^{* *} \\
(0.043)\end{array}$ \\
\hline$\beta_{2}, \log$ public health expenditure & $\begin{array}{l}-0.015 \\
(0.011)\end{array}$ & $\begin{array}{l}-0.033 \\
(0.021)\end{array}$ & $\begin{array}{l}-0.014 \\
(0.010)\end{array}$ & $\begin{array}{l}-0.026 \\
(0.018)\end{array}$ \\
\hline$\beta_{3}, \log$ private health expenditure & $\begin{array}{l}-0.029 \\
(0.015)\end{array}$ & $\begin{array}{l}-0.018 \\
(0.022)\end{array}$ & $\begin{array}{l}-0.025 \\
(0.013)\end{array}$ & $\begin{array}{l}-0.019 \\
(0.020)\end{array}$ \\
\hline$\beta_{4}$, water & $\begin{array}{c}-0.005^{* *} \\
(0.002)\end{array}$ & $\begin{array}{c}-0.006^{* *} \\
(0.002)\end{array}$ & $\begin{array}{l}-0.003 \\
(0.002)\end{array}$ & $\begin{array}{c}-0.005^{* *} \\
(0.002)\end{array}$ \\
\hline$\beta_{5}$, sanitation & $\begin{array}{c}-0.006^{* *} \\
(0.002)\end{array}$ & $\begin{array}{l}-0.004 \\
(0.002)\end{array}$ & $\begin{array}{c}-0.005^{* *} \\
(0.002)\end{array}$ & $\begin{array}{l}-0.003 \\
(0.002)\end{array}$ \\
\hline$\beta_{6}$, immunization DPT & $\begin{array}{c}0.008 \\
(0.0004)\end{array}$ & $\begin{array}{c}0.005^{* *} \\
(0.001)\end{array}$ & $\begin{array}{c}0.001^{* *} \\
(0.0003)\end{array}$ & $\begin{array}{l}0.005^{* *} \\
(0.001)\end{array}$ \\
\hline$\beta_{7}$, immunization measles & $\begin{array}{c}-0.001^{* *} \\
(0.0004)\end{array}$ & $\begin{array}{c}-0.005^{* *} \\
(0.001)\end{array}$ & $\begin{array}{c}-0.0009^{* *} \\
(0.0003)\end{array}$ & $\begin{array}{c}-0.004^{* *} \\
(0.001)\end{array}$ \\
\hline$\tau_{1}$, trend & $\begin{array}{c}-0.018^{* *} \\
(0.002)\end{array}$ & $\begin{array}{c}-0.024^{* *} \\
(0.005)\end{array}$ & $\begin{array}{c}-0.018^{* *} \\
(0.002)\end{array}$ & $\begin{array}{c}-0.022^{* *} \\
(0.004)\end{array}$ \\
\hline$\tau_{2}$, trend $(\geq 2000)$ & $\begin{array}{c}-0.009^{* *} \\
(0.002)\end{array}$ & $\begin{array}{l}-0.001 \\
(0.005) \\
\end{array}$ & $\begin{array}{c}-0.007^{* *} \\
(0.002) \\
\end{array}$ & $\begin{array}{r}-0.0008 \\
(0.005) \\
\end{array}$ \\
\hline No. of observations & 1982 & 1595 & 1982 & 1595 \\
\hline No. of countries & 129 & 129 & 129 & 129 \\
\hline$R^{2}$ & 0.91 & 0.85 & 0.91 & 0.85 \\
\hline Underidentification test, $\chi^{2}(15)$ & & $35.6^{* *}$ & & $35.6^{* *}$ \\
\hline Hansen- $J$ test, $\chi^{2}(14)$ & & 17.3 & & 15.5 \\
\hline Endogeneity test, $\chi^{2}(7)$ & & $20.3^{*}$ & & $19.7^{* *}$ \\
\hline
\end{tabular}

$* p<0.05, * * p<0.01$ Standard errors in parentheses are heteroskedastic and autocorrelation-robust.(OLS) All explanatory variables are exogenous. (IV-GMM) All explanatory variables except trends and fixed effects are endogenous. Instruments are lags 1-3. Estimated using two-step feasible GMM. Tests are the Anderson canonical correlations test with a null hypothesis of underidentification, the Hansen J-test with the null hypothesis of valid instruments and the difference-in-Hansen endogeneity test with the null hypothesis of exogenous regressors. 
Table 7 : Regression results - trend specifications

\begin{tabular}{|c|c|c|c|c|c|}
\hline & \multicolumn{5}{|c|}{ log U5M } \\
\hline & $(3)$ & $(3 a)$ & $(3 \mathrm{~b})$ & $(3 \mathrm{c})$ & $(3 \mathrm{~d})$ \\
\hline$\beta_{1}, \log \mathrm{GDP}$ & $\begin{array}{c}-0.178^{* *} \\
(0.048)\end{array}$ & $\begin{array}{c}-0.221^{* *} \\
(0.043)\end{array}$ & $\begin{array}{c}-0.182^{* *} \\
(0.048)\end{array}$ & $\begin{array}{c}-0.226^{* *} \\
(0.043)\end{array}$ & $\begin{array}{c}-0.125^{* *} \\
(0.036)\end{array}$ \\
\hline$\beta_{2}, \log$ public health expenditure & $\begin{array}{c}-0.033 \\
(0.021)\end{array}$ & $\begin{array}{c}-0.027 \\
(0.017)\end{array}$ & $\begin{array}{l}-0.035 \\
(0.020)\end{array}$ & $\begin{array}{c}-0.031 \\
(0.018)\end{array}$ & $\begin{array}{c}-0.004 \\
(0.021)\end{array}$ \\
\hline$\beta_{3}, \log$ private health expenditure & $\begin{array}{c}-0.018 \\
(0.022)\end{array}$ & $\begin{array}{c}-0.025 \\
(0.019)\end{array}$ & $\begin{array}{c}-0.019 \\
(0.022)\end{array}$ & $\begin{array}{c}-0.027 \\
(0.019)\end{array}$ & $\begin{array}{c}-0.012 \\
(0.016)\end{array}$ \\
\hline$\beta_{4}$, water & $\begin{array}{c}-0.006^{* *} \\
(0.002)\end{array}$ & $\begin{array}{c}-0.006^{* *} \\
(0.002)\end{array}$ & $\begin{array}{c}-0.006^{* *} \\
(0.002)\end{array}$ & $\begin{array}{c}-0.005^{* *} \\
(0.002)\end{array}$ & $\begin{array}{c}-0.003 \\
(0.003)\end{array}$ \\
\hline$\beta_{5}$, sanitation & $\begin{array}{l}-0.004 \\
(0.002)\end{array}$ & $\begin{array}{c}-0.003 \\
(0.002)\end{array}$ & $\begin{array}{l}-0.004 \\
(0.002)\end{array}$ & $\begin{array}{c}-0.003 \\
(0.002)\end{array}$ & $\begin{array}{c}0.002 \\
(0.003)\end{array}$ \\
\hline$\beta_{6}$, immunization DPT & $\begin{array}{c}0.005^{* *} \\
(0.001)\end{array}$ & $\begin{array}{c}0.003^{* *} \\
(0.001)\end{array}$ & $\begin{array}{c}0.005^{* *} \\
(0.001)\end{array}$ & $\begin{array}{c}0.003^{* *} \\
(0.001)\end{array}$ & $\begin{array}{c}0.002 \\
(0.001)\end{array}$ \\
\hline$\beta_{7}$, immunization measles & $\begin{array}{c}-0.005^{* *} \\
(0.001)\end{array}$ & $\begin{array}{c}-0.004^{* *} \\
(0.001)\end{array}$ & $\begin{array}{c}-0.005^{* *} \\
(0.001)\end{array}$ & $\begin{array}{c}-0.004^{* *} \\
(0.001)\end{array}$ & $\begin{array}{c}-0.004^{* *} \\
(0.001)\end{array}$ \\
\hline$\tau_{1}$, trend & $\begin{array}{c}-0.024^{* *} \\
(0.005)\end{array}$ & $\begin{array}{c}-0.024^{* *} \\
(0.002)\end{array}$ & & & \\
\hline$\tau_{2}$, trend $(\geq 2000)$ & $\begin{array}{l}-0.001 \\
(0.005)\end{array}$ & & & & \\
\hline Fixed effects & YES & YES & YES & YES & YES \\
\hline Level breaks & YES & $\mathrm{NO}$ & YES & YES & $\mathrm{NO}$ \\
\hline Time effects & $\mathrm{NO}$ & $\mathrm{NO}$ & YES & YES & $\mathrm{NO}$ \\
\hline Country-specific trends & $\mathrm{NO}$ & $\mathrm{NO}$ & $\mathrm{NO}$ & $\mathrm{NO}$ & YES \\
\hline No. of observations & 1595 & 1595 & 1595 & 1595 & 1853 \\
\hline No. of countries & 129 & 129 & 129 & 129 & 129 \\
\hline$R^{2}$ & 0.85 & 0.78 & 0.85 & 0.78 & 0.96 \\
\hline Underidentification test & $35.6^{* *}$ & $52.8^{* *}$ & $35.0^{* *}$ & $52.6^{* *}$ & $17.1^{* *}$ \\
\hline Hansen- $J$ test & 17.3 & 21.5 & 17.2 & 21.7 & 0.6 \\
\hline Endogeneity test & $20.3^{* *}$ & $14.6^{*}$ & $22.1^{* *}$ & $16.7^{*}$ & $38.1^{* *}$ \\
\hline
\end{tabular}

$* p<0.05, * * p<0.01$ Standard errors in parentheses are heteroskedastic and autocorrelation-robust. Estimated using two-step feasible GMM. All explanatory variables except trends and fixed effects are endogenous. Instruments are lags 1-3 except (3d) where instruments are 1st lags and trend break. Tests are the Anderson canonical correlations test with a null hypothesis of underidentification $\left(\chi^{2}(2)\right.$ in (3d) and $\chi^{2}(15)$ elsewhere), the Hansen- $J$ test with the null hypothesis of valid instruments $\left(\chi^{2}(1)\right.$ in $(3 \mathrm{~d})$ and $\chi^{2}(14)$ elsewhere) and the difference-in-Hansen endogeneity test with the null hypothesis of exogenous regressors $\left(\chi^{2}(7)\right)$. 


\section{FIGURES}

Figure 1: Under-five mortality rates for developing countries by year

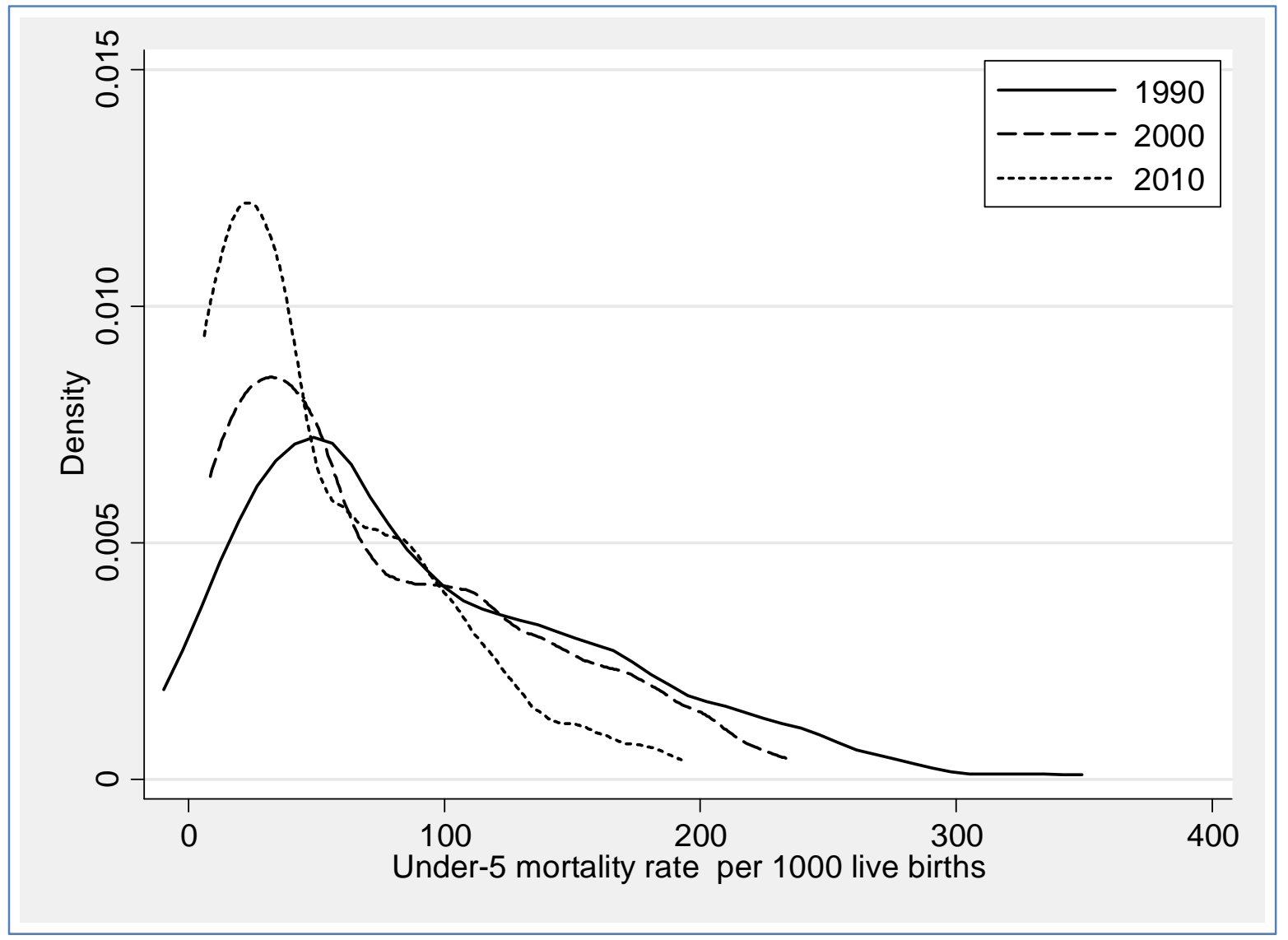

Note: Calculated using the Epanechnikov kernel with optimal bandwidth. Densities are scaled so that the area under each graph is 1. 
Figure 2 : Annual rate of decrease of under-five mortality rates in developing countries 2000-2010

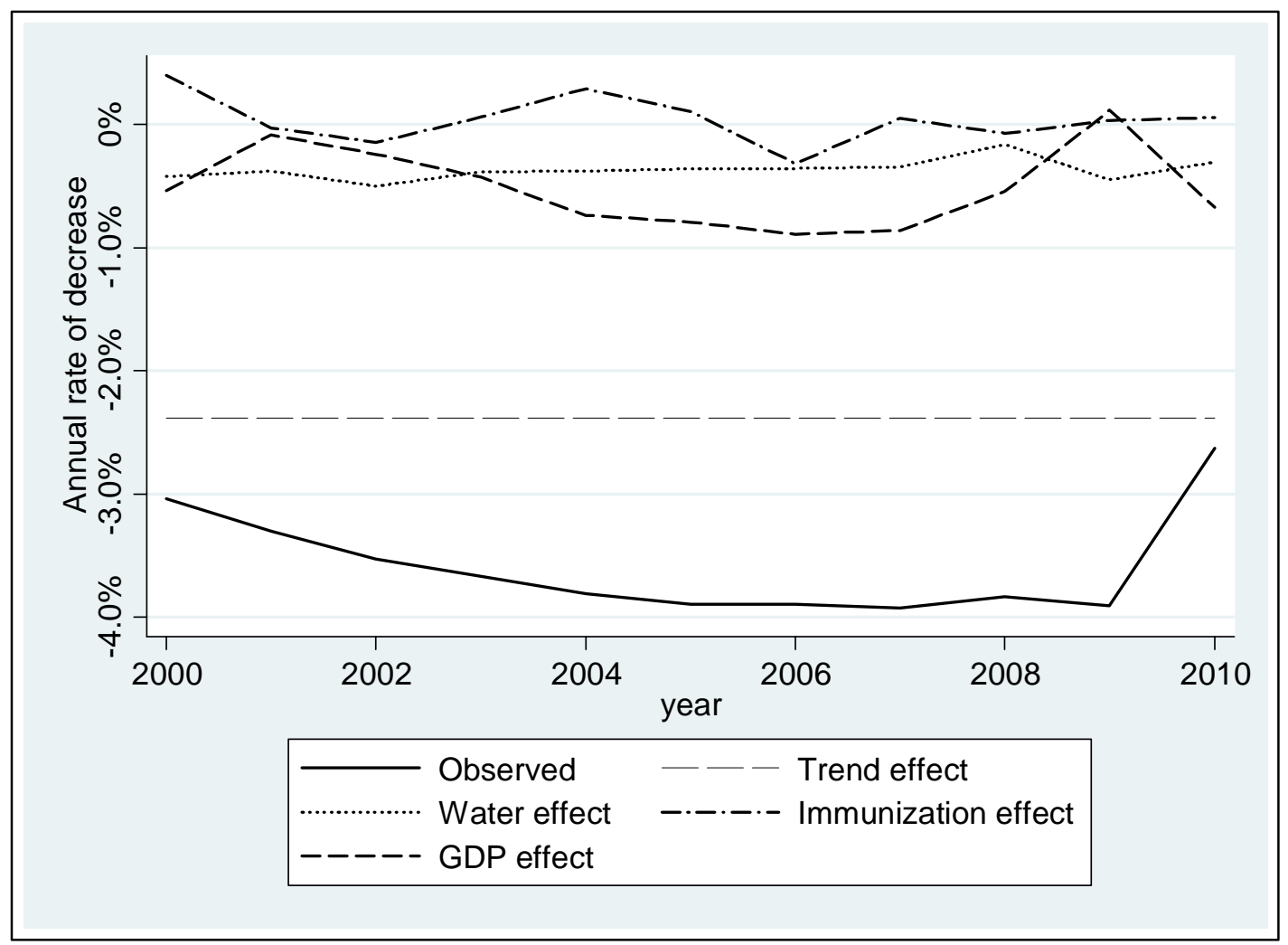

Note: Estimates from Table 6 applied to the annual change in the averages of the explanatory variables in Model 3. GDP effect is $\left(\beta_{1}\left\{{\overline{\log (\mathrm{GDP})_{t}}}_{t}-{\overline{\log (\mathrm{GDP})_{t-1}}}_{t}\right\}\right)$, Water effect is $\left(\beta_{4}\left\{\overline{\text { Water }}_{t}-\overline{\text { Water }}_{t-1}\right\}\right)$ and Immunization effect is $\left(\beta_{6}\left\{\overline{\text { ImmDPT }}_{t}-\overline{\text { ImmDPT }}_{t-1}\right\}+\beta_{7}\left\{\overline{\text { ImmMeasles }}_{t}-\overline{\text { ImmMeasles }}_{t-1}\right\}\right)$ 